\title{
TFIIE Subunit Gene
}

National Cancer Institute

\section{Source}

National Cancer Institute. TFIIE Subunit Gene. NCI Thesaurus. Code C20647.

TFIIE Subunit Genes encode 2 subunit proteins of $56 \mathrm{kD}$ and $34 \mathrm{kD}$. TFIIE is a heterotetramer of 2 alpha and 2 beta subunits, both subunits being required for optimal basal-level transcription. Both subunits are essential to form a stable preinitiation complex. High levels of gene transcription by RNA polymerase II depend on high rates of transcription initiation and reinitiation. Initiation requires recruitment of the complete transcription machinery to a promoter, a process facilitated by activators and chromatin remodeling factors. Reinitiation occurs through a different pathway. After initiation, a subset of the transcription machinery remains at the promoter, forming a platform for assembly of a second transcription complex as a scaffold for formation of a functional reinitiation complex. Formation of this scaffold depends on ATP and TFIIH. Some activators and Mediator may promote high levels of transcription. (from OMIM 189962). 